\title{
LUGAR DA EDUCAÇÃO DAS RELAÇÕES ÉTNICO-RACIAIS NOS PROJETOS POLÍTICO-PEDAGÓGICOS DE DUAS ESCOLAS PARAENSES
}

\author{
Wilma de Nazaré Baía Coelho ${ }^{1}$ \\ Kátia Evangelista Regis² \\ Carlos Aldemir Farias da Silva ${ }^{3}$
}

\begin{abstract}
RESUMO
O objetivo deste artigo, é analisar o lugar da Educação das Relações Étnico-Raciais (ERER) nos Projetos Político-Pedagógicos (PPPs) de duas escolas paraenses, com base em seus documentos escolares, PPPs e do Plano de Desenvolvimento Institucional (PDI) de uma delas. Recorremos a Bardin (2016) para a categorização dessa empiria. Acionamos Veiga (2003) para a ponderação sobre Projeto PolíticoPedagógico; e sua implementação em Gomes (2012). Para a ERER e a escola, recorremos a Coelho e Coelho $(2013,2018)$. Concluímos que o trabalho realizado por ambas as escolas possibilita, ainda que de forma pontual, uma discussão junto aos discentes, com vistas à problematização da identidade, racismo e discriminação, embora não reflita a institucionalidade e a implementação da ERER nos documentos escolares.
\end{abstract}

Palavras-chave: Escola Básica. Educação das Relações Étnico-Raciais. Projeto Político-Pedagógico. Currículo.

\footnotetext{
1 Doutora em Educação (UFRN). Professora Associada IV da Universidade Federal do Pará UFPA - Belém - Pará - Brasil. Professora dos Programas de Pós-Graduação em Educação em rede na Amazônia (EDUCANORTE) Educação em Ciências e Matemáticas (PPGCEM/UFPA) e Educação em Currículo e Gestão da Escola Básica (PPEB/UFPA). Coordenadora do Núcleo de Estudos e Pesquisas sobre Formação de Professores e Relações Étnico-Raciais (NEAB/GERA/UFPA). Bolsista de Produtividade em Pesquisa ID do CNPq. ORCID iD: https://orcid.org/0000-0001-8679-809X.E-mail: wilmacoelho@yahoo.com.br

2 Doutora em Educação (PUC-SP). Professora Associada II da Universidade Federal do Maranhão - UFMA - São Luís - Maranhão - Brasil. Pesquisadora do Núcleo de Estudos AfroBrasileiros (UFMA) e Núcleo Interdisciplinar em Estudos Afro-Brasileiros (UFMA). ORCID iD: https://orcid.org/0000-0002-4104-1963. E-mail: katia_educ@yahoo.com.br

3 Doutor em Ciências Sociais - Antropologia (PUC-SP). Professor da Universidade Federal do Pará - UFPA - Belém - Pará - Brasil. Professor do Programa de Pós-Graduação em Educação em Ciências e Matemáticas (PPGCEM/UFPA). Pesquisador do Núcleo de Estudos e Pesquisas sobre Formação de Professores e Relações Étnico-Raciais (NEAB/GERA/UFPA). ORCID iD: https://orcid.org/0000-0001-5463-1316. E-mail: carlosfarias1 @gmail.com.br
} 


\title{
EDUCATION FOR ETHNIC-RACIAL RELATIONS IN POLITICAL-PEDAGOGICAL PROJECTS OF TWO SCHOOLS AT PARÁ - BRAZIL
}

\begin{abstract}
This article aims to analyze how Education for Ethnic-Racial Relations (EERR) is represented in Political-Pedagogical Projects (PPPs) of two schools at Pará (Brazil), based on their school documents, PPPs and also the Institutional Development Plan (PDI) of one of such schools. Bardin (2016) was consulted to categorize this empiricism. Veiga (2003) was studied to consider the Political-Pedagogical Project, and its implementation was according to Gomes (2012). To analyze EERR and school, Coelho and Coelho $(2013,2018)$ were referred. It was concluded that the work carried out by both schools, albeit occasionally, allows discussion with students, in order to problematize identity, racism and discrimination. However, it does not reflect institutionality and implementation of EERR in school documents.
\end{abstract}

Keywords: Elementary School. Education for Ethnic-Racial Relations. PoliticalPedagogical Project. Curriculum.

\section{EL LUGAR DE LA EDUCACIÓN DE LAS RELAÇÕES ÉTNICO-RACIALES EN LOS PROYECTOS POLITÍCOS PEDAGÓGICOS DE DOS ESCOLAS EN EL ESTADO DE PARÁ}

\section{RESÚMEN}

El propósito de este artículo es analizar el lugar de la Educación en Relaciones Étnico-Raciales (ERER) en los Proyectos Político-Pedagógicos (PPP) de dos escuelas de Pará, a partir de sus documentos escolares, PPP y el Plan de Desarrollo Institucional (PDI) de Una de ellas. Usamos Bardin (2016) para categorizar este empirismo. Llamamos a Veiga (2003) para considerar el Proyecto PolíticoPedagógico; y su implementación en Gomes (2012). Para ERER y la escuela, usamos Coelho y Coelho $(2013,2018)$. Concluimos que el trabajo realizado por ambas escuelas permite, aunque de manera oportuna, una discusión con los estudiantes, con miras a problematizar la identidad, el racismo y la discriminación, aunque no refleja la institucionalidad y la implementación de ERER en los documentos escolares.

Palabras-clave: Escuela Básica. Educación de las Relaciones Étnico-Raciales. Proyecto Político-Pedagógico. Currículo.

\section{INTRODUÇÃO}

A implementação da Lei n. 10.639/20034, que tornou obrigatório o ensino da história e cultura afro-brasileira e africana, vem suscitando, há

\footnotetext{
${ }^{4}$ A Lei n. 11.645, de 10 de março de 2008, altera a LDB, anteriormente modificada pela Lei $n$. 10.639, para incluir no currículo oficial da Rede de Ensino a obrigatoriedade da temática "História e Cultura Afro-Brasileira e Indígena".
} 
alguns anos, debates densos e tensos em torno do conhecimento que é percebido socialmente como importante para ser incorporado nas instituições educacionais. Com a aprovação da referida Lei5, como decorrência de processo histórico de lutas do Movimento Negrob, a abordagem da temática Educação das Relações Raciais (ERER) no campo educacional tem sido incorporada, em diferentes níveis de implementação, no decorrer dos anos, possibilitando a abertura de espaços diversos para as discussões sobre a discriminação, o racismo e seus efeitos nas relações estabelecidas pelos/as estudantes nos diferentes níveis de ensino.

Contudo, para que ocorra a inserção da história e cultura afro-brasileira e africana nas práticas educativas em consonância com as Diretrizes Curriculares para a Educação das Relações Étnico-Raciais (DCNERER) (BRASIL, 2004), faz-se necessária a implementação da referida Lei, por meio da regulamentação nos documentos normativos e de planejamento dos estabelecimentos de ensino, na exigência da criação de grupos de trabalhos sobre o tema e na garantia de condições humanas, materiais e financeiras para a execução de projetos sobre a temática e mecanismos de avaliação da efetivação da Lei.

De acordo com o Plano Nacional de Implementação das DCNERER para o ensino de história e cultura afro-brasileira e africana (BRASIL, 2009, p. 38), as escolas, por intermédio das redes de ensino, deverão incorporar nos projetos político-pedagógicos os conteúdos propostos pela Lei n. 11.645/08, com base nas regulamentações dos conselhos estaduais em todos os níveis e modalidades de ensino.

Em relação à atuação dos/as docentes, enfatiza-se no documento das DCNERER a importância do comprometimento destes com os valores e

\footnotetext{
${ }^{5}$ Altera a Lei que estabelece as diretrizes e bases da educação nacional (Lei n. 9.394/1996) para incluir no currículo oficial da Rede de Ensino a obrigatoriedade da temática "História e Cultura Afro-Brasileira". Importante enfatizar que, em 2008, esta lei foi modificada, estabelecendo a inclusão da temática indígena por meio da Lei n. 11.645/2008.

6 Nilma Lino Gomes defende a contribuição do Movimento Negro enquanto "produtor de saberes emancipatórios e de um sistematizador de conhecimentos sobre a questão racial no Brasil" (GOMES, 2017, p. 14). Outra reflexão nessa mesma premissa pontua que "Os movimentos sociais, indígenas e negros passam a apontar a necessidade de se repensar a educação para além do modelo eurocêntrico" (SILVA; SILVA; SILVA, 2019, p. 1).
} 
princípios estabelecidos na legislação que aborda a ERER e do engendramento dos preceitos deste aparato normativo nos processos de ensino-aprendizagem ofertados nos diferentes níveis de ensino (COELHO; COELHO, 2018).

Nosso argumento encontra-se na urgência do aprofundamento teórico sobre as discussões em torno da Lei n. 9.394/96, que define as diretrizes e bases da educação brasileira, e sua alteração a partir das Leis n. $10.639 / 2003^{7}$ e n. $11.645 / 2008$, pois representam uma medida efetiva para o combate à discriminação racial nas escolas brasileiras, uma vez que valoriza a cultura negra e o/a negro/a na formação da sociedade nacional. Tal urgência se agiganta, especialmente, em razão do contexto no qual as garantias de direitos conquistados e as políticas de ação afirmativa têm sido atingidas por atos de um estado conservador.

Neste sentido, a escola, como uma instituição social ${ }^{8}$, reflete em seu microcosmo, em grande medida, as representações de parte da sociedade, dentre as quais a discriminação racial, que responde à chamada?, sobejamente publicizada pela literatura especializada, a despontar como uma instância sobre a qual a discussão não pode ser silenciada. Não somente por sua natureza formativa de crianças e adolescentes, mas pela função social, como Brandão (2004) e Ilma Passos Veiga (2003) pontuaram, na medida em que atende às demandas sociais e suas expectativas coletivas. Afinal, "[...] reconhecem a escola como lugar da formação de cidadãos e afirmam a relevância da escola promover a necessária valorização das matrizes culturais que fizeram do Brasil o país rico, múltiplo e plural que somos" (BRASIL, 2009, p. 3).

Neste artigo, analisaremos o lugar da ERER nos Projetos PolíticoPedagógicos (PPPs) de duas escolas paraenses, tendo como base o

\footnotetext{
7 A Lei altera o Artigo 26-A, que passa ter o seguinte texto: "Art. 26-A. Nos estabelecimentos de ensino fundamental e médio, oficiais e particulares, torna-se obrigatório o ensino sobre história e cultura afro-brasileira" (BRASIL, 2003, art. 26-A).

8 Canário (2005).

9 Coelho e Coelho (2013).
} 
arcabouço legal10. Para tanto, realizaremos a análise dos PPPs dessas instituições públicas da Educação Básica localizadas em Belém do Pará para verificar se e/Ou como abordam a ERER e o ensino da história e cultura afrobrasileira e africana. Esta reflexão se insere como parte de uma pesquisa financiada pelo CNPq, a qual se ocupa em compreender a escola, as relações de sociabilidades estudantis e a ação pedagógica no que toca à Educação das Relações Étnico-Raciais.

No que tange ao percurso teórico e metodológico, para dar cobro de nosso objetivo, trabalhamos com os PPPs de ambas as escolas e o Plano de Desenvolvimento Institucional (PDI) de uma delas. Para a sistematização dessa empiria, apoiamo-nos nas ponderações de Laurence Bardin (2016), por meio da técnica de análise de conteúdo, em conformidade com suas três fases: a pré-análise, a exploração do material e o tratamento dos resultados, a partir da inferência e interpretação (condensação dos processos de codificação e categorização para o exercício de reflexão crítica interpretativa, de ida e volta à teoria, com vistas à interpretação da empiria).

Quanto à literatura especializada, acionamos ainda llma Passos Veiga para a reflexão sobre Projeto Político-Pedagógico. A respeito da implementação da Lei 10.639/2003 a partir das formulações de Gomes (2012). O binômio educação das relações étnico-raciais e escola foi investigado com base em Coelho e Coelho $(2013,2018)$.

\section{EDUCAÇÃO DAS RELAÇÕES ÉTNICO-RACIAIS E FORMULAÇÕES LEGAIS NO CURRÍCULO}

A promulgação da Lei n. 10.639/2003 favorece o reconhecimento, a valorização e a afirmação de direitos da população negra. Segundo as

\footnotetext{
10 A esse respeito, destacamos: a Lei n. 10.639/2003, a Lei n. 11.645/2008, as Diretrizes Curriculares Nacionais para a Educação das Relações Étnico-Raciais e para o Ensino de História e Cultura Afro-Brasileira e Africana (BRASIL, 2004), o Plano Nacional de Implementação das Diretrizes Curriculares Nacionais para a Educação das Relações ÉtnicoRaciais e para o Ensino da História e Cultura Afro-Brasileira e Africana (BRASIL, 2009), as Diretrizes Curriculares Nacionais para a Educação Escolar Quilombola (BRASIL, 2012a) e a Lei n. $12.711 / 2012$.
} 
Diretrizes Curriculares Nacionais para a Educação das Relações ÉtnicoRaciais e para o Ensino de História e Cultura Afro-Brasileira e Africana (BRASIL, 2004), a obrigatoriedade da inclusão desta temática implica, necessariamente, repensar as relações étnico-raciais, sociais, pedagógicas, procedimentos de ensino, condições oferecidas para a aprendizagem, objetivos tácitos e explícitos da educação escolar, bem como depende de condições físicas, materiais, intelectuais e afetivas para o processo de ensino e aprendizagem, executado por meio de ações que articulem processos educativos, políticas públicas e movimentos sociais.

Para a implementação do arcabouço legal que legisla sobre a obrigatoriedade do ensino da história e cultura afro-brasileira e africana, os sistemas de ensino e as instituições educacionais são desafiados a repensarem suas práticas educativas para que a inserção do tema não se limite a meros acréscimos de alguns conteúdos nos currículos eurocêntricos hegemônicos (COELHO; COELHO, 2013), o que requer transformações estruturais na lógica dos sistemas educativos para que possam integrar, de forma consistente e rigorosa, o ensino da temática. Deste modo, esta legislação auxilia na contestação da perspectiva eurocentrada que fundamenta as instituições educacionais, pois, segundo as DCNERER (BRASIL, 2004, p. 14), permanece no Brasil "[...] um imaginário étnico-racial que privilegia a brancura e valoriza principalmente as raízes europeias da sua cultura, ignorando ou pouco valorizando as outras, que são a indígena, a africana e a asiática".

Para tanto, é fundamental desestabilizar as práticas curriculares eurocêntricas para que a diversidade étnico-racial brasileira seja contemplada e para que o ensino da história e cultura afro-brasileira e africana seja estruturante das práticas curriculares em direção à construção da justiça curricular ${ }^{11}$. O eurocentrismo estruturante dos currículos contribui

\footnotetext{
11 Segundo Santomé (2016, p. 4), "La justicia curricular es el resultado de analizar el currículo que se legisla, diseña, pone en acción, evalúa e investiga, tomando en consideración el grado en el que todo lo que se decide y hace en las aulas es respetuoso y atiende a las necesidades y urgencias de todos los colectivos sociales; les ayuda a verse, analizarse, comprenderse y juzgarse en cuanto personas éticas, solidarias, colaborativas y
} 
para os processos de inferiorização e de subalternização em sociedades marcadas pelo racismo estrutural 12 , patriarcado e neoliberalismo, nas quais a exploração e dominação estão presentes em todas as esferas da vida. Neste contexto, a história e cultura africana e da diáspora é silenciada e/ou distorcida. Segundo García (2018, p. 59):

Cuando surge el eurocentrismo como eje hegemónico políticoideológico de dominación, lo hace sobre la base del desprecio hacia los "otros" pueblos del mundo, con fines totalmente económicos. Y detrás de eso, la descalificación con argumentos religiosos, intelectuales y biológicos. [...] Esa filosofía del desprecio se convirtió en "eurocentrismo" y de ahí pasó al "universalismo". Surge así el "clásico" eurocéntrico como resultado del geo-euro-narcisismo. En fin, el mundo comenzó girar alrededor de la hegemonía eurocéntrica occidental.

As instituições educacionais, bem como suas propostas pedagógicas, estão sendo tensionadas para subsidiarem mudanças para a realização de práticas curriculares em uma perspectiva intercultural crítica ${ }^{13}$ - o que não é simples, pois implica a alteração do modo como historicamente os currículos escolares foram estruturados, permanecendo ainda hoje fundamentados em uma concepção eurocêntrica, conforme apontam Coelho e Coelho (2018) acerca da permanência do eurocentrismo nas Instituições de Ensino Superior (IES).

O autor e a autora analisaram dez projetos político-pedagógicos de licenciaturas em História em diferentes regiões geográficas do Brasil. Nos referidos documentos, a Europa é o foco absoluto de atenção em disciplinas voltadas para a compreensão de processos que nela ocorreram, como é o

corresponsables de un proyecto más amplio destinado a construir un mundo más humano, justo y democrático".

${ }^{12}$ Sobre racismo estrutural, consultar Almeida (2018).

13 Conforme Walsh (2010, p. 78), con la perspectiva de la interculturalidad crítica, "no partimos del problema de la diversidad o diferencia en sí, sino del problema estructuralcolonial-racial, es decir, de un reconocimiento de que la diferencia se construye dentro de una estructura y matriz colonial de poder racializado y jerarquizado, con los blancos y "blanqueados" en la cima y los pueblos indígenas y afrodescendientes en los peldaños inferiores. Desde esta posición, la interculturalidad se entiende como una herramienta, como un proceso y proyecto que se construye desde la gente - y como demanda de la subalternidad -, en contraste a la funcional, que se ejerce desde arriba. Apuntala y requiere la transformación de las estructuras, instituciones y relaciones sociales, y la construcción de condiciones de estar, ser, pensar, conocer, aprender, sentir y vivir distintas".

Revista Exitus, Santarém/PA, Vol. 11, p. 01 - 24, E-location 020129, 2021. 
caso de História Antiga, História Medieval, História Moderna e História Contemporânea. Do mesmo modo, é o epicentro dos eventos que regulam processos em outras partes do globo (o que é habitual em disciplinas voltadas os processos de colonização da América, bem como em disciplinas relativas à História da África, História Indígena, História da América ou do Brasil independentes e nas disciplinas de natureza teórico-metodológica).

Na mesma direção, uma pesquisa em rede coordenada por Silva, Regis e Miranda (2018) revelou quão grandes são os desafios para que as instituições educacionais cumpram o arcabouço legal sobre o tema. Tal pesquisa definiu a produção acadêmica sobre a educação das relações étnico-raciais entre 2003 e 2014 por meio da análise das teses de doutorado e das dissertações de mestrado realizadas nos programas de pós-graduação stricto sensu em Educação no Brasil e em periódicos qualificados (A e B) na área da Educação, com base em 494 artigos, 476 dissertações e 122 teses da área de educação, e concluem que as pesquisas apontam a permanência do racismo de modo institucionalizado, bem como sugerem possibilidades de reflexão sobre tal reiteração.

Um dos destaques apontados na investigação é a necessidade de formação de professores/as sobre o tema. Associada a estes processos formativos, existe a necessidade da criação e/ou ampliação de grupos de trabalho nas secretarias estaduais e municipais de educação para o desenvolvimento e para a avaliação de ações acerca da ERER, bem como a articulação com outras políticas públicas que contemplem a diversidade étnico-racial brasileira. Também houve a ressalva da importância da inclusão da história e cultura afro-brasileira e africana nos PPPs das instituições de ensino (SILVA; REGIS; MIRANDA, 2018).

Conforme o referencial destacado, esse processo está apresentando desafios para que o ensino da história e cultura afro-brasileira e africana não seja efetuado de forma isolada, à margem do currículo hegemônico e restrito a docentes e/ou gestores/as comprometidos/as com o tema, mas que seja realizado em consonância com as DCNERER, tendo como princípios: a) a consciência política e histórica da diversidade; b) o 
fortalecimento das identidades e de direitos e c) ações educativas de combate ao racismo e às discriminações. Para a concretização da educação para as relações étnico-raciais e para o ensino da história e cultura afro-brasileira e africana, um aspecto a ser observado diz respeito à inserção da ERER nos Projetos Político-Pedagógicos das instituições de ensino.

De acordo com as DCNERER (BRASIL, 2004), as instituições educacionais deverão providenciar, entre outras questões: a inclusão nos documentos normativos e de planejamento dos estabelecimentos de ensino de todos os níveis - estatutos, regimentos, planos pedagógicos, planos de ensino - de objetivos explícitos, como também de procedimentos para sua consecução, com o objetivo do combate ao racismo, às discriminações e ao reconhecimento, à valorização e ao respeito à história e cultura afrobrasileira e africana. Com relação à importância do PPP da instituição educacional para propiciar a realização de uma educação antirracista, Carreira e Souza (2013) pontuam:

\begin{abstract}
O projeto político-pedagógico explicita, por escrito, o compromisso com a educação antirracista na escola? [...] No regimento interno da escola, há regras negociadas de postura e comportamentos diante de situações de racismo (sutis e explícitas) como forma de educação para a igualdade racial? [...] Na escola, articulado ao projeto político-pedagógico, há um esforço para a construção de um campo interdisciplinar que possa colocar em diálogo diversas áreas do conhecimento com foco na reeducação das Relações Étnico-raciais? (CARREIRA; SOUZA, 2013, p. 52-53).
\end{abstract}

A partir desta perspectiva, refletiremos acerca do espaço da ERER em dois projetos político-pedagógicos de instituições da Educação Básica de Belém do Pará: a escola do Telégrafo e a escola do Guamá ${ }^{14}$.O PPP é um instrumento que permite à comunidade escolar refletir sobre suas práticas, bem como expressar os caminhos que serão trilhados pela escola. Desse modo, a análise do documento pode possibilitar a reflexão em torno das intencionalidades do processo educativo em relação ao ensino da história e cultura afro-brasileira e africana.

14 Para resguardo às instituições, estas serão mencionadas aqui pelos bairros aos quais estão relacionadas.

Revista Exitus, Santarém/PA, Vol. 11, p. 01 - 24, E-location 020129, 2021. 


\section{A ERER E OS PROJETOS POLÍtICO-PEDAGÓGICOS DE DUAS ESCOLAS PARAENSES}

No Brasil, ocorreu um significativo avanço jurídico-político para a garantia dos direitos educacionais da população negra, um dos resultados das lutas coletivas dessa população. Isto, contudo, não quer dizer que a mera alteração do arcabouço legal implique a modificação das práticas, mas a própria lei é decorrência das contradições da realidade e também será com conflitos, lutas e tensões que ela poderá transformar as ações educativas. Apesar dos desafios, a legislação está contribuindo para a reflexão acerca das práticas curriculares eurocêntricas. Logo, é necessária a reflexão constante acerca da incompatibilidade entre o proposto no arcabouço legal vigente e o que se realiza nas instituições de ensino. Destarte, a inserção da temática terá mais possibilidades de concretização se for tensionada a maneira como as instituições escolares, seus PPPs e seus currículos organizaram-se historicamente.

Quanto à forma de análise dos dois projetos político-pedagógicos e do PDI, centramos-nos nos documentos escolares e na reflexão com a legislação sobre a educação das relações étnico-raciais. Quanto à forma de sistematização e reflexão, o corpo documental foi analisado tendo por base a metodologia da análise de conteúdo, tal como proposta por Laurence Bardin (2016). Assim, buscamos apreender os sentidos presentes nas formulações do conteúdo dos projetos políticos-pedagógicos das duas escolas e como esses eram incorporados na formulação dos documentos em tela, sobretudo na relação orgânica, quando possível, à legislação. Inicialmente, as categorias centrais sobre a ERER foram identificadas e catalogadas ao longo da reflexão sobre os PPPs. Tal organicidade se conformou, principalmente em relação as formas e frequências a partir das quais a Legislação para a diversidade refletiam sobre racismo, discriminação e preconceito. Tal análise se conformou, ainda, com vistas à compreensão do sentido subjacente a cada uma dessas categorias e em que nível essas encaminhavam as questões relativas à diversidade e à diferença no âmbito da formação de crianças e adolescentes sob a égide de tais documentos. 
A escola do Guamá foi criada em 07 de março de 1963, objetivando oferecer gratuitamente o então ensino primário para os/as filhos dos/as servidores ${ }^{15}$. Atualmente, a instituição de ensino tem a finalidade de

[...] atuar como Unidade Acadêmica de Ensino, Pesquisa e Extensão voltada para educação básica, técnica e tecnológica, atuando também, como campo de estágios, visando à produção, sistematização e socialização do conhecimento configurando-se como espaço de formação profissional, inovação pedagógica, articulando o Ensino Básico e o Ensino Superior (PPP ESCOLA DO GUAMÁ, 2014, p. 12).

A escola do Guamá funciona em três períodos e possui 65 turmas divididas da seguinte maneira: Educação Infantil (06 turmas, 70 estudantes); Ensino Fundamental I (17 turmas, 229 estudantes); Ensino Fundamental II (20 turmas, 421 estudantes); Ensino Médio (15 turmas, 398 estudantes); Ensino Noturno (07 turmas, 180 estudantes). A escola possui 57 servidores técnicoadministrativos/as; 173 docentes (efetivos/as e substitutos/as) e 29 bolsistas $^{16}$.

Conforme o Projeto Político-Pedagógico da escola do Guamá (PPP, 2014 , p. 6), "O Projeto Pedagógico (doravante PP) é um instrumento que define a identidade da instituição e orienta os caminhos que se pretende seguir, bem como seus princípios orientadores". Ademais, há o destaque de que o PP "[...] deve traduzir a visão, a missão, os princípios norteadores, os valores, os objetivos, as metas e as ações que orientam o caminho do sucesso e da autonomia a ser trilhado pela instituição escolar" (BRASIL, 2014, p. 7). Segundo o documento (BRASIL, 2014, p. 12), "Objetiva-se neste PP que a escola conceba o processo educativo numa perspectiva dialética, democrática, de respeito às individualidades e diversidades [...]".

A escola do Telégrafo foi criada em 13 de maio de 2003. A instituição funciona em três turnos, conta com 16 salas de aula e possui 81 docentes. Conforme o PPP da escola (PPP, 2018, p. 13), esse documento "[...] deve conter as necessidades, as conquistas e os sonhos da comunidade escolar a qual pertence, pois ele deverá servir para reflexão de toda a prática da escola, a partir da análise de seus objetivos e de suas finalidades". De

\footnotetext{
15 Atualmente, ampliou seu atendimento a toda a comunidade, via sorteio.

16 PPP (2014); PDI (2018).
}

Revista Exitus, Santarém/PA, Vol. 11, p. 01 - 24, E-location 020129, 2021. 
acordo com o PPP (2018, p. 11, grifo nosso), dentre seus objetivos, está a "formação de cidadãos críticos, eticamente orientados para o respeito às identidades". Eliane Cavalleiro (2001, p. 89), há quase duas décadas, ponderou que a tarefa da escola que quer ser cidadã não pode deixar de fora a "questão racial no seu currículo e na sua prática".

Conforme o discutido anteriormente, ainda são muitos os desafios para que a história e a cultura afro-brasileira e africana sejam abordadas com a consistência adequada. E um dos aspectos que pode possibilitar o ensino da temática é a inclusão do tema nos PPPs das escolas.

A ponderação de Ilma Passos Veiga (2003, p. 279) parece oportuna, ao afirmar que "é preciso construir um projeto político-pedagógico comprometido com as múltiplas necessidades sociais e culturais da população". O PPP da escola do Guamá afirma tal compromisso. Ao mencionar o "respeito às identidades", diz-nos muito do que a escola espera dos processos educativos. Ainda assim, vale destacar o alerta de Carreira e Souza (2013, p. 49) sobre um documento desta natureza na escola, de que muitas vezes é elaborado "[...] sem considerar a diversidade social e racial presente nas escolas". Assim, a despeito da relevância do registro, requer também uma referência concreta e específica em relação à diversidade com base na literatura especializada e nos documentos legais. Afinal, o alerta de Inês Oliveira parece pertinente neste momento em que "a perspectiva hegemônica a respeito da escola e àquilo que nela deveria acontecer fundamenta-se em critérios de padronização" (OLIVEIRA, 2013, p. 376).

O PPP da escola do Guamá (2014), o PD da escola (2018) e o PDI 20162025 da UFPA (2016) ressaltam questões que valem o destaque, tais como: "Valorizar a diversidade nos processos formativos" e 0 "combate qualquer tipo de discriminação" (PDI DA ESCOLA DO GUAMÁ, 2018, p. 51 e 26). Além disso destacamos ainda:

Valorização da autonomia, da responsabilidade, da solidariedade e do respeito ao bem comum, ao meio ambiente e 
às diferentes culturas, identidades e singularidades" (PPP ESCOLA DO GUAMÁ, 2014, p. 32);

Garantir a implementação da Lei N. 10.639/2003 de acordo com o preceito legal (PPP ESCOLA DO GUAMÁ, 2014, p. 37);

Produzir, socializar e transformar o conhecimento na Amazônia para a formação de cidadãos capazes de promover a construção de uma sociedade inclusiva e sustentável". (PDI ESCOLA DO GUAMÁ, 2016, p. 31). O respeito à ética e à diversidade étnica, cultural, biológica, de gênero e de orientação sexual (PDI DA ESCOLA DO GUAMÁ, 2016, p. 32). Esses princípios definem a "identidade" da instituição no que tange a ensino, em perspectivas tanto para Ilma Passos Veiga (2003), trata de um documento basilar para o direcionamento das atividades pedagógicas, quanto para Carlos Libâneo que expressa que esse documento define os objetivos, diretrizes e ações do processo educativo. Com aqueles princípios destacados, aqui, a escola do Guamá diz como se conformam seus princípios educacionais.

Quanto aos princípios orientadores que identificam a escola do Telégrafo, no que tange à questão da diversidade e das diferenças:

Respeito às diferenças individuais, sociais e culturais e pluralidade
de ideias e concepções (PPP ESCOLA DO TELÉGRAFO, 2018, p. 11).
Mas é acima de tudo assumir nosso compromisso com a causa
educativa e com a formação de seres mais éticos, críticos, livres,
conscientes de que são cidadãos planetários e que por isso
precisam assumir novas posturas frente ao mundo que se faz e se
refaz com muita velocidade e nos expõem a mudanças
inesperadas, as quais exigem um ser humano mais sensível para
viver e respeitar as diferenças, trabalhar coletivamente, conviver
com a diversidade sem perder a sua individualidade (PPP ESCOLA
DO TELÉGRAFO, 2018, p. 4, grifos nossos).

Um dos primeiros aspectos que suscitam reflexões a partir da análise dos PPPs das duas instituições de ensino diz respeito ao perfil dos/as estudantes. Nos documentos da Escola do Guamá, constam o gênero dos/as docentes, dos/as discentes e da equipe técnico-administrativa. $\mathrm{Na}$ escola do Telégrafo, não é mencionado o perfil de gênero de seus e suas integrantes. Contudo, nenhuma das escolas menciona o perfil étnico-racial dos seus e suas docentes, discentes e técnico-administrativos/as.

A dimensão étnico-racial é um dos aspectos fundamentais para observar como as instituições de ensino lidam com a ERER, bem como as desigualdades que emergem no cotidiano escolar a partir dos diferentes pertencimentos étnico-raciais. Por exemplo, no PPP da escola do Telégrafo, 
na Seção "Metas a serem alcançadas" consta "reduzir o índice de reprovação e de evasão escolar no ano de 2018" (PPP ESCOLA DO TELÉGRAFO, 2018, p. 20, grifo nosso). Seria significativo o enfoque étnicoracial para a redução dos índices de reprovação e de evasão escolar, pois há desigualdades entre a população negra e a população branca no acesso e na permanência nas instituições de ensino 17, especialmente no Ensino Fundamental e na passagem para o Ensino Médio (ZIVIANI, 2012).

Os dados estatísticos a partir do perfil étnico-racial são importantes, pois comprovam os diversos tipos de desigualdades a que está submetida a população negra; o constante processo de desumanização por meio da negação dos direitos e das violências física e simbólica; o menor acesso aos espaços de poder; como o Estado sistematicamente legitima práticas discriminatórias, bem como estas são naturalizadas e continuamente reafirmadas e legitimadas.

O arcabouço legal que legisla sobre a ERER indaga uma escola estruturada a partir da perspectiva do universalismo abstrato. A Lei n. 10.639/2003 colide com as práticas educativas presentes nos processos de escolarização em todos os níveis, etapas e modalidades de ensino, fortemente estruturadas a partir do mito da democracia racial e da ideologia do branqueamento. Portanto, esta política curricular voltada para a diversidade está problematizando as hierarquias e os privilégios na sociedade brasileira, na qual as diferenças têm sido tratadas como desigualdade e de forma discriminatória.

As ponderações de Nilma Lino Gomes e Rodrigo Jesus (2013) reforçam que o conjunto de dispositivos legais são indutores de uma política educacional voltada para a afirmação da diversidade cultural e da concretização de uma ERER nas escolas, desencadeada a partir da década de 2000. Assim, tal perspectiva, no nosso entendimento, deve figurar de modo estruturante nos documentos formais das escolas.

17 A esse respeito, consultar IBGE (2019). 
As ações educativas não podem pautar-se na perspectiva da igualdade abstrata que, na prática, resulta em tratamento desigual e hierárquico entre a população negra e a população branca e na manutenção de privilégios historicamente constituídos. É relevante o conhecimento do/a estudante real, em sua corporeidade, com diferentes pertencimentos étnico-raciais, haja vista que, conforme Santos $(2013$, p. 7879):

[...] a luta contra a discriminação e a exclusão deixou de ser uma luta pela integração e pela assimilação na cultura dominante e nas instituições subsidiárias, para passar a ser uma luta pelo reconhecimento da diferença, pela consequente transformação da cultura e das instituições de modo a separar as diferenças (a respeitar) das hierarquias (a eliminar) que atavicamente the estavam referidas.

Outro aspecto observado nos PPPs analisados diz respeito ao modo como a ERER e o ensino da história e cultura africana e afro-brasileira são abordados. Constatamos que há a menção em diferentes ocasiões dos temas da diversidade, diferença, educação inclusiva. Entretanto, tais referências não são sistematizadas por meio da indicação de ações concretas que possam subsidiar ações educativas que insiram estruturalmente a diversidade, não suscitam a problematização das desigualdades étnico-raciais existentes, bem como não subsidiam práticas educativas antirracistas. No PPP da escola do Telégrafo, por exemplo, no "Capítulo VI: Dos projetos educativos da escola", nenhum deles aborda explicitamente a ERER e o conhecimento sobre a História e Cultura Africana e da Diáspora. No PPP da escola do Guamá, no item "Cronograma de execução da Dimensão Pedagógica", o tema também não é destacado.

As simples alusões a temas como diversidade e diferença não desestabilizam a lógica eurocentrada das práticas educativas, que invisibilizam outras formas de pensar e de viver; não problematizam as implicações da colonialidade naquilo que é selecionado para integrar os currículos escolares; não problematizam os processos de subordinação, hierarquização e desigualdades geradoras da exclusão das maiorias e que 
afetam particularmente a população negra. Ocorre o ocultamento das relações de dominação, o que contribui para a reprodução das desigualdades.

Walsh (2010) destaca que, desde os anos 1990, a interculturalidade tornou-se um tema da moda. Está presente nas políticas públicas e nas reformas educacionais e constitucionais e é uma questão importante no âmbito institucional nacional, bem como na esfera inter/transnacional. Não obstante, há a argumentação que essa deferência é um dos resultados das lutas dos movimentos político-sociais ancestrais e de suas reivindicações por reconhecimento, direitos e transformação social, mas também pode ser percebida por outro ângulo: relacionada aos projetos globais de poder, do capital e do mercado. Utilizado em variados contextos e com interesses muitas vezes opostos, o entendimento do conceito é amplo e difuso. Conforme a autora, uma das perspectivas é a denominada interculturalidade funcional: está fundada no reconhecimento da diversidade e da diferença cultural, com objetivos voltados para sua inclusão na estrutura social estabelecida, ou seja, é "funcional" ao sistema existente, pois não interfere nas causas da assimetria e das desigualdades, sendo compatível com a lógica neoliberal.

Na mesma direção, Rincón (2018) destaca que a interculturalidade na América Latina adquire um caráter menos acadêmico: o lócus de enunciação dos povos indígenas e afro-latinos/as na construção da interculturalidade não apenas muda em relação às políticas multiculturalistas das potências globais, mas também se separa dos governos latinoamericanos, cujo tratamento das questões interculturais não faz diferença com as práticas do multiculturalismo como doutrina de Estado. Dessa forma, os estados latino-americanos respondem perfeitamente aos postulados da democracia liberal: a interculturalidade na perspectiva do multiculturalismo não representa outra coisa senão políticas de inclusão direcionadas a comunidades, povos e nacionalidades consideradas com déficits sociais históricos. Mas esta inclusão, equivocadamente chamada de intercultural, não objetiva realizar nenhuma mudança substancial, nenhuma 
transformação das relações de poder: pelo contrário, esse tipo de medidas de inclusão deixa intacta a estrutura social e econômica baseada em profundas desigualdades.

\section{CONCLUSÕES}

Afirmamos que o trabalho coletivo por ambas as escolas possibilita, ainda que de forma pontual, uma discussão junto aos discentes, com vistas à problematização da equidade racial, identidade, racismo e discriminação, permitindo que essas questões sejam objeto de inflexão por parte de alguns discentes e docentes.

Na escola do Guamá, os resultados com base nos documentos, apontam uma intenção da escola para o trabalho com a autonomia, solidariedade, identidade e a garantia da implementação da Lei № 10.639/2003. No PDI dessa escola, fica clara a correlação de tal intenção na garantia de pautas escolares que enfrentem pedagogicamente 0 preconceito de toda ordem, tal qual explicita O PPP. No entanto, a concretização dessa premissa centra-se nas efemérides e, também, em alguns projetos de iniciativas pessoais de docentes - aqueles/as que estão envolvidos/as com a temática ou aquele/as integrantes do Movimento Negro. Dentre os projetos de iniciativas individuais, ainda que acompanhados pela Escola, encontramos o Projeto Afrocientista o qual estabelece o diálogo entre os/as estudantes da Educação Básica com a Universidade, de modo a auxilia-los/as na discussão sobre o enfrentamento pedagógico do racismo no Brasil e a ampliação de perspectivas desses/as estudantes para o ingresso à Educação Superior.

$\mathrm{Na}$ escola do Telégrafo, respeito às diferenças e diversidade, pluralidade de concepções, estão presentes nos princípios norteadores do PPP da escola. Assim, como também a discussão sobre cidadania, com vistas à construção de competências para assunção de novas posturas desse corpo discente frente às injustiças sociais. Entretanto, apesar dessa menção no PPP relativa à discussão sobre a diversidade e inclusão, a sua concretalização, focaliza-se em ações pontuais e específicas, sobretudo nas 
efemérides, mas não se desdobra em aprendizagens significativas em relação à aplicação dessas discussões nas relações sociais dos/as estudantes dessa escola, o que não difere estruturalmente da escola anterior. Dentre os projetos desenvolvidos pela escola do Telégrafo, existe o Projeto Afrocientista, em parceria com a ABPN e a Universidade, exatamente como na escola anterior, objetiva o trabalho com os estudantes com vistas à autonomia e a identidade étnico-racial.

Ambas as instituições estiveram envolvidas com o projeto Afrocientista, financiado pela Associação Brasileira de Pesquisadores Negros (ABPN) e Instituto Unibanco e, em especial, a escola do Guamá acolhe, desde o ano de 2013, um projeto sobre a temática étnico-racial, o qual envolve estudos de parte do Ensino Médio. Nessas escolas, ocorre o fenômeno apontando por José Bonifácio Silva e Giceli Cervi (2020), de que

Por vezes, o debate sobre as discriminações não está presente na escola por causa de uma forte tradição seletiva do currículo que exclui essa discussão, muito embora os cotidianos escolares também sejam, ocasionalmente, afetados por atividades que visam combater discriminações e preconceitos inferiorizantes a partir de reelaborações curriculares efetuadas em relações e práticas nas escolas (SILVA; CERVI, 2020, p. 13).

Contudo, as ações não somente pedagógicas, mas de debates, ainda que existam, conformam-se em ações pontuais, pois não refletem institucionalidade a implementação dessa temática nos documentos orientadores da escola.

Petronilha Beatriz Gonçalves e Silva (2007) afirma que, embora reconheçamos as dificuldades de implantar políticas curriculares na perspectiva da diversidade, torna-se imperativo debater a contribuição da matriz africana e indígena para a conformação da cultura nacional.

Atualmente, não é possível anunciar ausência de material didático e de pesquisas sobre 0 tema ${ }^{18}$. Parece-nos que o contexto nos convida a estabelecer um compromisso para além do que regulam o arcabouço legal

18 Silva, Regis e Miranda (2018); Coelho (2018). 
e a literatura especializada sobre o tema, pois estratégias pedagógicas têm sido produzidas nos últimos 15 anos, as quais abarcam tais dimensões em âmbito escolar ${ }^{19}$.

Reafirmamos a urgência de novos debates com participação das IES, dos movimentos sociais, dos sindicatos, de organismos públicos e privados, Associações científicas brasileiras (ANPOCS, ANPED, ANPUH, ABPN, dentre outras) e professores/as da Educação superior de todas as áreas do conhecimento e da Educação Básica interessados/as no fortalecimento de uma Educação Antirracista para fazer valer os direitos conquistados e a (re)formulação de políticas públicas para uma educação que refute um currículo monocultural. Internamente, é preciso reiterar a discussão da temática sobre a Educação para a ERER nos processos formativos na Educação Superior e na Educação Básica, não apenas mencionar de modo protocolar, como apontam Coelho e Coelho (2018), mas fazê-lo de modo circunstanciado.

Acionamos a reflexão de Romualdo Oliveira (2018) de que, "se é verdade que uma lei não muda a realidade, também é verdade que uma lei que reconhece e estabelece mecanismos para garantir direitos muito ajuda na luta social. A CF/88, nessa perspectiva, foi muito importante", com quem concordamos, pois não podemos recuar em relação aos direitos conquistados, frutos de luta coletiva. A escola não pode ser responsável por tudo, mas deve garantir que a discussão sobre a diversidade que a conforma seja debatida de forma circunstanciada, com vistas a uma educação antirracista e efetivamente democrática.

19 Programa Ética e Cidadania: construindo valores na escola e na sociedade - relações étnico-raciais na escola e de gênero (2007); Leitura e Práticas Discursivas Étnico-raciais em Aulas de Língua Portuguesa (2019); Gestão Escolar para a Educação das Relações Étnicoraciais, de gênero e diversidade sexual. Unidade 1 - Educação das Relações Étnico-raciais (2018); construindo as Relações Étnico-Raciais: projeto com sugestão de ações para construir as relações étnico-raciais na escola (2020); Currículo da Cidade: povos indígenas orientações pedagógicas (2019); Escola básica e relações raciais (2019); Travessias Atlânticas e a Paraíba Afro-Diaspórica. Conexões, conhecimentos e saberes: Extensão, ensino e pesquisa para uma educação das relações étnico-raciais (2019); Orientações e Ações para a Educação das Relações Étnico-Raciais (2006); Educação infantil, igualdade racial e diversidade: aspectos políticos, jurídicos, conceituais (2012); $1^{\circ}$ Caderno Pedagógico Educação e Diversidade: Implantação e implementação das leis $n^{\circ} 11.645 / 08, n^{\circ} 10.639 / 03$, $n^{\circ} 11.525 / 07$ e n 9.795/99 na educação básica e modalidades de ensino (2016). 


\section{REFERÊNCIAS}

ALMEIDA, S. O que é racismo estruturale Belo Horizonte: Letramento, 2018.

BRASIL. Diretrizes Curriculares Nacionais para a Educação Escolar

Quilombola. Brasília: MEC/CNE/CEB, 2012a. Disponível em:

http://portal.mec.gov.br/index.php?option=com_docman\&view=download \&alias= 1 1963-rceb008-12-pdf\&category_slug=novembro-2012-

pdf\&ltemid=30192. Acesso em: 15 fev. 2021

BRASIL. Lei n. 12.711, de 29 de agosto de 2012. Dispõe sobre o ingresso nas universidades federais e nas instituições federais de ensino técnico de nível médio e dá outras providências. Diário Oficial da União, Brasília, 30 ago. $2012 b$.

BRASIL. Plano Nacional de Implementação das Diretrizes Curriculares Nacionais para a Educação das Relações Étnico-Raciais e para o Ensino de História e Cultura Afro-Brasileira e Africana. Brasília: MEC/SEPPIR, 2009. Disponível em: http://www.planalto.gov.br/ccivil_03/_ato20112014/2012/lei/l12711.htm. Acesso em: 15 fev. 2021

BRASIL. Lei n. 11.645, de 10 de março de 2008. Altera a Lei n. 9.394, de 20 de dezembro de 1996, modificada pela Lei n. 10.639, de 9 de janeiro de 2003, que estabelece as Diretrizes e Bases da Educação Nacional, para incluir no currículo oficial da rede de ensino a obrigatoriedade da temática "História e Cultura Afro-Brasileira e Indígena". Diário Oficial da União, Brasília, 11 mar. 2008. Disponível em: http://www.planalto.gov.br/ccivil_03/_ato20072010/2008/lei/l1 1645.htm. Acesso em: 15 fev. 2021

BRASIL. Programa Ética e Cidadania: construindo valores na escola e na sociedade - relações étnico-raciais na escola e de gênero. Brasília: SEB/MEC, 2007. Disponível em:

http://portal.mec.gov.br/seb/arquivos/pdf/Etica/1_rel_etica.pdf. Acesso em: 30 jan. 2020.

BRASIL. Orientações e Ações para a Educação das Relações Étnico-Raciais. Brasília: MEC/SECAD, 2006. Disponível em:

http://portal.mec.gov.br/dmdocuments/orientacoes_etnicoraciais.pdf. Acesso em: 01 dez. 2020.

BRASIL. Diretrizes Curriculares Nacionais para a Educação das Relações Étnico-Raciais e para o Ensino de História e Cultura Afro-Brasileira e Africana. Brasília: MEC/SEPPIR, 2004. Disponível em:

http://www.vel.br/projetos/leafro/pages/arquivos/DCN-s\%20-

\%20Educacao\%20das\%20Relacoes\%20Etnico-Raciais.pdf. Acesso em: 15 fev. 2021. 
BRASIL. Lei n. 10.639, de 9 de janeiro de 2003. Altera a Lei n. 9.394, de 20 de dezembro de 1996, que estabelece as Diretrizes e Bases da Educação Nacional, para incluir no currículo oficial da Rede de Ensino a obrigatoriedade da temática "História e Cultura Afro-Brasileira", e dá outras providências. Diário Oficial da União, Brasília, 10 jan. 2003. Disponível em: http://www.planalto.gov.br/ccivil_03/leis/2003/l10.639.htm\#: :text=L 10639\&te $\mathrm{xt}=\mathrm{LEI} \% 20$ No\%2010.639\%2C\%20DE\%209\%20DE\%20JANEIRO\%20DE\%202003.\&tex $\mathrm{t}=$ Altera\%20a\%20Lei\%20no,\%22\%2C\%20e\%20d\%C3\%A 1\%20outras\%20provid\%C 3\%AAncias.. Acesso em: 15 fev. 2021

BRASIL. Lei n. 9.394, de 20 de dezembro de 1996. Estabelece as Diretrizes e Bases da Educação Nacional. Diário Oficial da União, Brasília, 23 dez.1996. Disponível em: http://www.planalto.gov.br/ccivil_03/leis/19394.htm. Acesso em: 15 fev. 2021

BARDIN, L. Análise de conteúdo. Lisboa: Edições 70, 2016.

BENTO, M. A. S. (Org.). Educação infantil, igualdade racial e diversidade: aspectos políticos, jurídicos, conceituais. São Paulo: CEERT, 2012. Disponível em:

www.educadores.diaadia.pr.gov.br/arquivos/File/cadernos_pedagogicos/e dinf_igualdade.pdf. Acesso em: 30 nov. 2020.

BRANDÃO, C. R. O que é educação? 43. ed. São Paulo: Brasiliense, 2004 (Coleção Primeiros Passos).

CANÁRIO, R. O que é a escola? Um "olhar" sociológico. Porto: Porto Editora, 2005.

CAVALLEIRO, E. Racismo e Anti-racismo na Educação: repensando nossa escola. São Paulo: Selo Negro Edições, 2001.

CARREIRA, D.; SOUZA, A. L. S. Indicadores da qualidade na educação:

relações raciais na escola. São Paulo: Ação Educativa, 2013. Disponível em: http://www.acaoeducativa.org.br/relacoesraciais/wpcontent/uploads/2013/12/IndicadoresRR_vf.pdf. Acesso em: 14 ago. 2020.

COELHO, W. de N. B. Formação de professores e relações étnico-raciais (2003-2014): produção em teses, dissertações e artigos. Educar em Revista, Curitiba, v. 34, n. 69, p. 97-122, mai./jun. 2018. Disponível em:

https://revistas.ufpr.br/educar/article/view/57233. Acesso em:1 1 nov. 2020. COELHO, W. de N. B.; COELHO, M. Cr. Os conteúdos étnico-raciais na educação brasileira: práticas em curso. Educar em Revista, v. 29, n. 47, p. 6784, jan./mar. 2013. Disponível em: https://bityli.com/UsGwL. Acesso em: 1 nov. 2020. 
COELHO, M. C.r; COELHO, W. de N. B. As licenciaturas em história e a lei 10.639/03: percursos de formação para o trato com a diferença? Educação em Revista, Belo Horizonte, v. 34, p. 1-39, 2018. Disponível em: https://www.scielo.br/pdf/edur/v34/1982-6621-edur-34-e192224.pdf. Acesso em: 12 nov. 2020.

GÁRCIA, J. C. Afroepistemología y pedagogíacimarrona. In: MIRANDA, C. M. et al. Editado por Rosa Campoalegre Septien. Afrodescendencias: voces en resistencia en homenaje al Centenario de Nelson Mandela. Ciudad Autónoma de Buenos Aires: CLACSO, 2018, p. 59-70. Disponível em: http://biblioteca.clacso.edu.ar/clacso/se/20180712070816/Afrodescendenci as.pdf. Acesso em: 01 abr. 2020.

GOMES, N. L. O movimento negro educador: saberes construídos nas lutas por emancipação. Petrópolis, RJ: Vozes, 2017.

GOMES, N. L. Relações étnico-raciais, educação e descolonização dos currículos. Currículo sem Fronteiras, v.12, n. 1, jan./abr., p. 98-109, 2012. Disponível em:

http://www.curriculosemfronteiras.org/vol12iss l articles/gomes.pdf. Acesso em: 20 set. 2019.

GOMES, N. L.; JESUS, R. E. de. As práticas pedagógicas de trabalho com relações étnico-raciais na escola na perspectiva de Lei 10.639/2003: desafios para a política educacional e indagações para a pesquisa. Educar em Revista, Curitiba, Brasil, n. 47, p. 19-33, jan./mar. 2013.

IBGE. Síntese de indicadores sociais: uma análise das condições de vida da população brasileira. Rio de Janeiro: IBGE/Coordenação de População e Indicadores Sociais, 2019. Disponível em:

https://biblioteca.ibge.gov.br/visualizacao/livros/liv101678.pdf Acesso em: 03 mar. 2020.

OLIVEIRA, I. B. de. Currículo e processos de aprendizagem ensino: políticas práticas educacionais cotidianas. Currículo sem Fronteiras, v. 13, n. 3, p. 375391, set./dez., 2013. Disponível em:

http://www.curriculosemfronteiras.org/vol13iss3articles/oliveira.pdf. Acesso em: 15 fev. 2021.

OLIVEIRA, R. P. de. A Constituição de 1988 e o Direito à Educação. Anped, Rio de Janeiro, 14 mai. 2018. Disponível em:

http://www.anped.org.br/news/constituicao-de-1988-e-o-direito-educacaopor-romualdo-portela-de-oliveira-feusp. Acesso em: 11 nov. 2020.

RINCÓN, J. E. G. Interculturalidade e racismo no centro-periferia do circuito: contribuição crítica na perspectiva da negritude. Revista da Associação Brasileira de Pesquisadores/as Negros/as (ABPN), [S.I.], v. 10, n. 26, P. 27-56, 
out. 2018. ISSN 2177-2770. Disponível em:

http://www.abpnrevista.org.br/revista/index.php/revistaabpn l/article/view/6 36. Acesso em: 16 ago. 2019.

SANTOMÉ, J. T. Justicia curricular y laurgencia de volver a repensar elcurrículum escolar. Intervención el Coloquio: Curriculum - Sociedad: Voces, Tensiones y Perspectivas. México DF, v. 11, 12, 13 y 14 de Octubre de 2016. Disponível em: https://jurjotorres.com/?p=5127 Acesso em: 20 dez. 2018.

SANTOS, B. de S. Direitos humanos, democracia e desenvolvimento. In: SANTOS, B. de S.; CHAUÍ, M. Direitos humanos, democracia e desenvolvimento. São Paulo: Cortez, 2013, p. 41-133.

\section{SECRETARIA DE EDUCAÇÃO. $1^{\circ}$ Caderno Pedagógico Educação e}

Diversidade: Implantação e implementação das leis $n^{\circ} 11.645 / 08, n^{\circ}$ 10.639/03, n 11.525/07 e n 9.795/99 na educação básica e modalidades de ensino. Santa Catarina: DIOESC, 2016. Disponível em: OP_7774 ADP_02677 Caderno Pedagógico - Educação e... www.sed.sc.gov.br > documentos । file (google.com.br). Acesso em: 30 nov. 2020.

\section{SECRETARIA DE ESTADO DE EDUCAÇÃO DO PARANÁ. Gestão Escolar para a} Educação das Relações Étnico-raciais, de gênero e diversidade sexual. Unidade 1 - Educação das Relações Étnico-raciais: histórico, fundamentos e exclusão da população negra. Curitiba, PR: SEDUC, 2018. Disponível em: http://www.gestaoescolar.diaadia.pr.gov.br/arquivos/File/gestao_em_foco/ diversidade_unidadel.pdf. Acesso em: 30 nov. 2020.

SECRETARIA DE ESTADO DE EDUCAÇÃO, CULTURA E ESPORTES. Construindo as Relações Étnico-raciais: projeto com sugestão de ações para construir as relações étnico-raciais na escola. Rio Branco-AC: SEE, 2020. Disponível em: https://drive.google.com/file/d/15KmrkyXKg4U_6uLDg_tSec8I54DhL6G/view?† $s=5 f c 54 e 53$. Acesso em: 29 nov. 2020.

SECRETARIA MUNICIPAL DE EDUCAÇÃO. Currículo da Cidade: povos indígenas - orientações pedagógicas. São Paulo: SME/COPED, 2019. Disponível em: https://educacao.sme.prefeitura.sp.gov.br/wpcontent/uploads/Portals/1/Files/53254.pdf. Acesso em: 30 nov. 2020.

SILVA, J. B. A. da; CERVI, G. M. Docentes de escolas públicas diante de práticas discriminatórias no cotidiano escolar. Revista Teias. v. 21, ago. 2020. Edição Especial. Disponível em: https://www.e-

publicacoes.uerj.br/index.php/revistateias/article/view/42171. Acesso em: 15 fev. 2021.

SILVA, J. B. da; SILVA, E. F. da; SILVA, E. J. L. da. Educação e diferença: diálogos e perspectivas. Roteiro, Joaçaba, v. 44, n. 2, p. 1-6, mai./ago. 2019. Disponível em: 
https://portalperiodicos.unoesc.edu.br/roteiro/article/view/21524 Acesso em: 27 nov. 2020.

SILVA; P. V. B.; REGIS, K.; MIRANDA, S. Educação das Relações Étnico-raciais no Brasil 1994-2014: síntese das pesquisas. In: SILVA; P. V. B.; REGIS, K.;

MIRANDA, S. (Orgs.). Educação e Relaçōes Étnico-Raciais: o Estado da Arte. Curitiba: NEAB-UFPR, 2018. p. 651-669. Disponível em:

https://www.membros.abpn.org.br>. Acesso em: 20 ago. 2019.

SILVA, P. B. G. e. Aprender, ensinar e relações étnico-raciais no Brasil. Revista Educação, Porto Alegre, ano XXX, n. 3, p. 63, set./dez. 2007. Disponível em: https://revistaseletronicas.pucrs.br/ojs/index.php/faced/article/view/2745/20 92. Acesso em: 15 fev. 2021.

UNIVERSIDADE FEDERAL DO PARÁ. Plano de Desenvolvimento Institucional 2016-2025. Belém: UFPA, 2016. Disponível em: https://portal.ufpa.br/images/docs/PDI_2016-2025.pdf. Acesso em: 15 fev. 2021.

VEIGA, I. P. A. Inovações e projeto político-pedagógico: uma relação regulatória ou emancipatória? Cadernos Cedes, Campinas, v. 23, n. 61, p. 267-281, dez. 2003. Disponível em:

https://www.scielo.br/pdf/ccedes/v23n61/a02v2361.pdf. Acesso em: 11 nov. 2020.

WALSH, C. Interculturalidad crítica y educación intercultural. In: VIANA, J.; TAPIA, L.; WALSH, C. Construyendo Interculturalidad Crítica. La Paz: Instituto Internacional de Integración del Convenio Andrés Bello, 2010, p. 75-96. Disponível em: https://pt.slideshare.net/tiagovarges/construyendo-lainterculturalidad-crtica. Acesso em: 20 abr. 2020.

ZIVIANI, D. C. das G. A cor das palavras: Alfabetização de crianças negras entre o estigma e a transformação. Belo Horizonte: Mazza Edições, 2012. p. $15-26$.

Recebido em: 23.12.2020

Aprovado em: 15.03.2021

Publicado em: 19.03.2021 